\title{
EDITORIAL
}

\author{
Paola Barreto Bedoya \\ Docente Investigador, Universidad de Boyacá, Tunja, Colombia. \\ Correspondencia: Dirección: Carrera 2 Este № 64-169 Tunja, Boyacá, Colombia; 7450000 ext 1102. \\ Correo electrónico: paolabarreto@uniboyaca.edu.co
}

\section{La Ciencia bien ordenada, su racionalidad y la democratización de la investigación científica.}

Se entiende la ciencia bien ordenada como la posibilidad de organizar las decisiones científicas de acuerdo con las prioridades de los contextos y las necesidades de los seres humanos, del mismo modo, se puede interpretar como la mejor manera de seleccionar los procesos, procedimientos y recursos que tendrán que ser empleados para llevar a feliz término las investigaciones.

De acuerdo con Kitcher, la ciencia bien ordenada se debe caracterizar por lograr concertar escenarios de deliberación, en virtud de los proyectos e intervenciones en investigación científica, que permitan ordenar las prioridades de acción y los métodos más eficientes para llevarlos a cabo, pensando siempre en todas las perspectivas y los intereses de los que están comprometidos con la generación de nuevo conocimiento (1).

La toma de decisiones en investigación científica se ha constituido tradicionalmente en un punto álgido de discusión, ya que involucra el encuentro de diferentes intereses que chocan de manera conflictiva, especialmente cuando se decide que o quienes van a investigar.

Cuando se aborda el componente de democratización en la toma de decisiones, se debe considerar la probable respuesta a los mecanismos, estrategias, motivaciones e intereses que inclinan la balanza hacia un tipo de decisiones específicas. Según Kitcher, democratizar la ciencia no consiste en someter a escrutinio público y universal, todas y cada una de las decisiones en ciencias, porque esto sería una tarea titánica y de hecho inconcebible, desde el punto de vista de la concertación humana (2). 
Plantear un punto medio, que permita por un lado responder efectivamente a las demandas y necesidades sociales y por otro lado permita lograr el avance de la ciencia a partir de investigaciones de vanguardia, se convierte en el mayor reto al que se enfrenta cualquier decisor en ciencia.

En los contextos no democráticos, la ciencia cumple con la labor de satisfacer los intereses ideológicos, de clase, de régimen, de género etc, por el contrario, en los contextos democráticos, las políticas científicas deben perseguir el bien común.

Decidir democráticamente en ciencia, debería permitir a los seres humanos ver justamente representados sus intereses para la resolución concreta de los problemas que aquejan a la comunidad, es decir, que permitan obtener el bien común, pero a la vez, debería permitir a los científicos, de acuerdo con la consideración de dichos intereses, tomar las mejores decisiones de priorización, dejando a un lado los propios intereses y teniendo presentes las justificaciones académicas, científicas y de asignación de recursos que consideren profesionalmente suficientes para realizar la mejor elección.

En este contexto, y de acuerdo con las propuestas de Popper, el criterio de racionalidad en el método científico consiste en la forma de operar dentro de la ciencia, dando las mejores razones para obtener un determinado fin. Proceder racionalmente en ciencia es proceder a través de las pautas del método científico como método crítico que responde al hecho de rechazar alternativas y quedarse con razones explicativas. La racionalidad para él es instrumental (medios y fines) y reconoce que es incompleta porque no discute la racionalidad de los fines (3).

La ciencia es racional pero el conocimiento es vulgar, de igual manera, la racionalidad es producto de la discusión critica entre los miembros de una comunidad científica respecto a las hipótesis y teorías vigentes, por tanto, está cargada de un cúmulo de elecciones, discusiones y conocimientos que, justificados en la observación y experimentación, cumplirán los objetivos de corroboración o refutación.

“El desarrollo de nuestro conocimiento, de nuestra manera de elegir entre las teorías, frente a determinados problemas, es lo que da carácter racional a las ciencias (1). 


\section{REFERENCIAS}

1. Gómez, R. (1995). Neoliberalismo y seudociencia, Buenos Aires, Lugar Editorial.

2. Gómez, R. (2014). Neoliberalismo fin de la historia y después. Buenos Aires, Argentina, Punto de Encuentro.

3. Popper, K. R. (1973). La miseria del historicismo, Madrid, Alianza.

\section{(ㅇ) (1)}

Esta obra está bajo una licencia de Creative Commons

Reconocimiento-NoComercial 4.0 Internacional 